\title{
Bile Duct
}

National Cancer Institute

\section{Source}

National Cancer Institute. Bile Duct. NCI Thesaurus. Code C12376.

Any of the ducts conveying bile between the liver and the intestine, including hepatic, cystic, and common bile duct. 